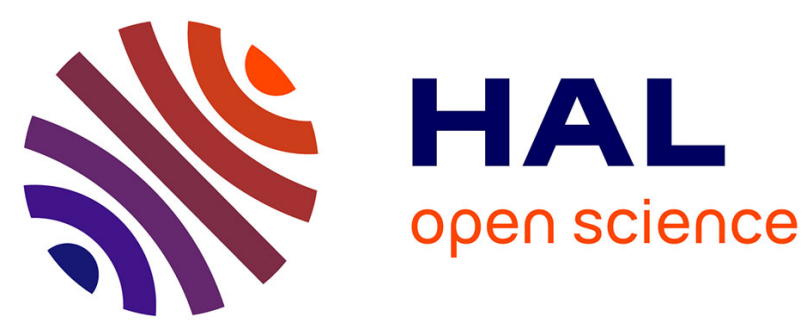

\title{
Effectiveness of conservative medical treatment for non-tubal ectopic pregnancies a multicenter study
}

S. Delplanque, M. Le Lous, M. Flévin, E. Bauville, P.Y. Moquet, L. Dion, A.

Fauconnier, S. Guérin, J. Leveque, V. Lavoué, et al.

\section{- To cite this version:}

S. Delplanque, M. Le Lous, M. Flévin, E. Bauville, P.Y. Moquet, et al.. Effectiveness of conservative medical treatment for non-tubal ectopic pregnancies a multicenter study. Journal of Gynecology Obstetrics and Human Reproduction, 2020, 49 (10), pp.101762. 10.1016/j.jogoh.2020.101762 . hal02638430

\section{HAL Id: hal-02638430 \\ https://hal-univ-rennes1.archives-ouvertes.fr/hal-02638430}

Submitted on 17 Jul 2020

HAL is a multi-disciplinary open access archive for the deposit and dissemination of scientific research documents, whether they are published or not. The documents may come from teaching and research institutions in France or abroad, or from public or private research centers.
L'archive ouverte pluridisciplinaire HAL, est destinée au dépôt et à la diffusion de documents scientifiques de niveau recherche, publiés ou non, émanant des établissements d'enseignement et de recherche français ou étrangers, des laboratoires publics ou privés. 


\section{Journal Pre-proof}

Effectiveness of conservative medical treatment for non-tubal ectopic pregnancies: a multicenter study

Sophie Delplanque, Maela Le Lous, Marie Flévin, Estelle Bauville, Pierre Yves Moquet, Ludivine Dion, Arnaud Fauconnier, Sonia

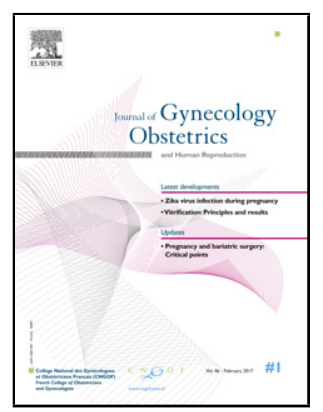

Guérin, Jean Leveque, Vincent Lavoué, Krystel Nyangoh Timoh

PII: $\quad$ S2468-7847(20)30105-7

DOI: $\quad$ https://doi.org/10.1016/j.jogoh.2020.101762

Reference: $\quad$ JOGOH 101762

To appear in: $\quad$ Journal of Gynecology Obstetrics and Human Reproduction

Please cite this article as: Delplanque S, Lous ML, Flévin M, Bauville E, Moquet PY, Dion L, Fauconnier A, Guérin S, Leveque J, Lavoué V, Timoh KN, Effectiveness of conservative medical treatment for non-tubal ectopic pregnancies: a multicenter study, Journal of Gynecology Obstetrics and Human Reproduction (2020), doi: https://doi.org/10.1016/j.jogoh.2020.101762

This is a PDF file of an article that has undergone enhancements after acceptance, such as the addition of a cover page and metadata, and formatting for readability, but it is not yet the definitive version of record. This version will undergo additional copyediting, typesetting and review before it is published in its final form, but we are providing this version to give early visibility of the article. Please note that, during the production process, errors may be discovered which could affect the content, and all legal disclaimers that apply to the journal pertain.

(C) 2020 Published by Elsevier. 


\section{Original Article}

Title: Effectiveness of conservative medical treatment for non-tubal ectopic pregnancies: a multicenter study.

Running Title: Conservative medical management for non-tubal ectopic pregnancies is effective.

Sophie Delplanque, $\mathrm{MD}^{1,2}$, Maela Le Lous, $\mathrm{MD}^{1,2}$, Marie Flévin, $\mathrm{MD}^{1}$, Estelle Bauville $\mathrm{MD}^{1,3}$, Pierre Yves Moquet, $\mathrm{MD}^{4}$, Ludivine Dion, MD, $\mathrm{PHD}^{1,2}$, Arnaud Fauconnier MD, $\mathrm{PhD}^{4}$, Sonia Guérin, MD, PHD ${ }^{1,2}$ Jean Leveque, MD, PHD ${ }^{1,2}$, Vincent Lavoué MD, PHD ${ }^{1,2}$, Krystel Nyangoh Timoh, MD, PHD ${ }^{1,2}$

${ }_{1}^{1}$ Department of Obstetrics and Gynecology, CHU Rennes Hospital, 35000 Rennes, France. ${ }^{2}$ Université de Rennes 1:2 avenue de Professeur Léon Bernard, 35000, Rennes, France ${ }^{3}$ Department of Gynecology and Obstetrics, CHI Poissy-St-Germain, 78300 Poissy, France ${ }^{4}$ Department of Gynecology and Obstetrics, Clinique mutualiste La sagesse, 35000 Rennes, France

\section{Correspondence:}

Doctor Nyangoh Timoh Krystel.

Service de Gynécologie-Obstétrique. Hôpital Sud Rennes. 16 Boulevard de Bulgarie 35000 Rennes. France.

Tel: +3372136050

Email: krystel.NYANGOH.TIMOH@chu-rennes.fr

\section{ABSTRACT}

Objective: To assess the effectiveness of conservative treatment for the management of nontubal ectopic pregnancies (NTEP) 
Methods: Retrospective cohort study in three centers (two referral centers) of patients managed for NTEP diagnosed by 2D or 3D ultrasonograhy. Patients underwent one of the following: expectant management, systemic methotrexate (MTX) injection, local MTX injection, combined MTX injection (local and systemic), local injection of hyperosmolar glucose, or misoprostol administration. The primary endpoint was final success defined by resolution of hCG level without need for emergency surgical treatment. Sixty-four patients diagnosed with NTEP were included: $37(57 \%)$ had an interstitial pregnancy, $23(35.9 \%)$ a cesarean scar pregnancy, two (3.1\%) a cervical pregnancy and two $(3.1 \%)$ an ovarian pregnancy.

Results: Six patients (9.4\%) underwent expectant management, $24(37.5 \%)$ a systemic MTX injection, $28(43.8 \%)$ a local injection of MTX, three (4.7\%) a combined MTX injection, one $(1.6 \%)$ a local injection of hyperosmolar glucose $(1.6 \%)$, and two $(3.1 \%)$ were administered misoprostol. The median age was 32 years (22-45) and mean follow-up was 41 months. The final success rate overall was $92.2 \%: 100 \%$ for expectant management, $87.5 \%$ for systemic MTX, $96.4 \%$ for local MTX, $100 \%$ for combined injection of MTX, $100 \%$ for local injection of hyperosmolar glucose, and $50 \%$ for misoprostol. No patient required a hysterectomy. Nine (14.1\%) patients required surgery, including five $(7.8 \%(5 / 64))$ following a rupture of the NTEP.

Conclusions: Our results suggest that conservative medical management of NTEP is effective and safe and should be the first-line treatment for pauci-symptomatic patients with an NTEP.

Keywords: Cesarean scar pregnancy; Interstitial pregnancy; Local methotrexate; Non-tubal ectopic pregnancy; Systemic methotrexate. 


\section{Introduction}

Ectopic pregnancy (EP) accounts for 1 to $2 \%$ of all pregnancies. The term EP includes tubal ectopic pregnancy [1, 2], which is the most common form, and non-tubal ectopic pregnancy (NTEP), which is rare and accounts for fewer than $10 \%$ of all EPs [3-6].. Compared with TEPs, they are associated with a higher mortality, life-threatening hemorrhage and emergency surgery such as hysterectomy $[7,8]$. Recent advances in imaging techniques have facilitated earlier diagnosis, which allow non-surgical treatment for patients with few symptoms or nonlife threatening NTEP.

In the setting of NTEP, because of its low incidence, no consensus exists for the therapeutic management. Case series indicate that minimally invasive management like local (or "in situ") injection of MTX can be safe and effective in the setting of NTEP, but also systemic MTX [9]. In contrast, the therapeutic strategy for TEP is well codified and a high success rate $(82 \%$ to $95 \%$ ) is obtained with injection of systemic methotrexate (MTX) which constitutes the standard medical treatment [10].

We conducted a retrospective study to assess the efficacy of conservative medical management of NTEP in a large multicentric case series. 


\section{Materials and Methods}

\subsection{Study Design}

We conducted a multicenter retrospective study from January 2008 to March 2018 at University Hospital of Rennes, the Intercommunal Hospital of Poissy, and La Sagesse Medical Center (Rennes), France. The study was approved by the Ethics Committee of the National College of the French Gynecologists and Obstetricians (CEROG 2018-GYN-1201).

\subsection{Patients}

We included women aged over 18 years who had been diagnosed with interstitial (IP), cervical $(\mathrm{CP})$, cesarean scar (CSP) or ovarian (OP) pregnancies (figure 1) by 2D or 3D ultrasonography and managed by primary medical treatment. Patients managed by primary surgery were excluded as well as patients with tubal, cornual (i.e pregnancy developed in the horn of a uterus with congenital malformation), or abdominal pregnancy.

The cases were identified using the PMSI (the French hospital medical information system) diagnostic code for "ectopic pregnancy" for patients consulting with gynecological emergencies of the three departments. All cases were reviewed and classified according to the location of the pregnancy if the NTEP was confirmed by ultrasound findings.

\subsection{Management of NTEP}

\subsubsection{Choice of therapeutic option}

Therapeutic options included: expectant management (EM), systemic (intramuscular) injection of MTX (IM-MTX), local injection of MTX (L-MTX), combined injection (systemic and local) of MTX (C-MTX), local injection of hyperosmolar glucose, or oral misoprostol. The therapeutic option was chosen by the physician based on the patient's symptomatology, the location of the pregnancy and the hCG level. Similarly, the on-call physician decided whether or not to prescribe adjuvant treatment depending on the decrease in hCG levels and progression of the patient's symptoms. 
All the patients were monitored clinically and biologically at least weekly, with control of hCG levels until the level fell below $5 \mathrm{UI} / \mathrm{L}$. A pelvic ultrasound was systematically performed on the 7th day or in the case of symptoms or stagnation of hCG, and at resolution.

2.3.2. Expectant management (EM): This approach was reserved for patients with no or few symptoms and consisted of a weekly clinical exam and hCG monitoring until resolution.

2.3.3. Systemic injection of MTX (IM-MTX): Patients with normal pre-therapeutic lab workup were eligible for IM-MTX. The dose of MTX used was $50 \mathrm{mg} / \mathrm{m} 2$ of the body surface area.

2.3.4. Local injection of MTX (L-MTX): Similarly, patients eligible for L-MTX had to have a normal pre-therapeutic lab work-up. The dose of MTX used was $1 \mathrm{mg} / \mathrm{kg}$ or $50 \mathrm{mg} / \mathrm{m}^{2}$ body surface area according to the operator. The approach was either laparoscopic or utrasoundguided transvaginal under local or general anesthesia depending on the location of the pregnancy, its accessibility via the vaginal route and the clinical condition of the patient. The vaginal approach was the preferred route when possible. All L-MTX procedures began with mechanical aspiration of the contents of the gestational sac, followed by slow installation of MTX. The material used included a 16 or $18 \mathrm{G}$ oocyte puncture needle for the ultrasoundguided transvaginal route, and an $18 \mathrm{G}$ catheter for the laparoscopic approach.

2.3.5. Combined MTX injection (C-MTX): This approach consisted of IM- and L-MTX administration on the same day at a dose of $1 \mathrm{mg} / \mathrm{kg}$ per injection. The pre-therapeutic lab work-up had to be normal.

2.3.6. Local injection of hyperosmolar glucose serum: This protocol was the same as for L-MTX using a dose of hyperosmolar (30\%) glucose solution.

2.3.7. Oral misoprostol: The dosage was six $200 \mu \mathrm{g}$ tablets divided into three intakes at 4 hourly intervals

\subsubsection{Additional treatments}

Additional treatments were decided on by the medical team and included: 
Medical treatment: An additional treatment by injection of MTX, systemic or local, was carried out if the hCG level had increased, stagnated or decreased by $<15 \%$ of the initial level on the 7th day, or when the pregnancy was found to be progressing on ultrasound.

Surgical management: A surgical procedure was performed if trophoblastic retention tissue was diagnosed on ultrasound, or if there was suspicion of a rupture. The specific approach was decided on according to the clinical status of the patient and the location of the pregnancy.

\subsection{Endpoints}

The primary endpoint was the final success rate of the conservative medical treatment for NTEP. Management was considered to be successful when the hCG level had dropped to $<5$ IU/L. Failure was defined by the need for emergency surgical treatment for life-threatening hemorrhage.

Secondary endpoints were: evaluation of initial success; i.e. success of the primary management (without any additional medical or surgical treatment).

\subsection{Collected data}

Data were collected from ultrasound image archives or imaging reports, and review of the electronic or paper medical records.

Gestational age was determined according to the last menstrual period and ultrasound findings.

The hCG monitoring values were collected and time to hCG and ultrasound resolution recorded on successful management.

The time to $\mathrm{hCG}$ and imaging resolution, time to obtain a decrease of $\geq 15 \%$ in $\mathrm{hCG}$, treatment toxicity and complications, and the obstetric outcome are also reported.

Complete sonographic resolution was defined by the absence of a gestational sac without trophoblastic retention or any other anomaly on transvaginal ultrasound.

\subsection{Statistical analysis}


Statistical analysis was based on the Student's t test for continuous variables, and the Chi-square test for categorical variables, as appropriate. A P-value $<0.05$ were considered to denote significant differences. 


\section{Results}

\subsection{Characteristics of the patient population}

During the study period, 76 patients were diagnosed with NTEP. Twelve patients were excluded: one because of an abdominal pregnancy diagnosed in the 2 nd trimester and 11 because of a first-line surgical management. Finally, 64 patients with conservative medical management of NTEP were included. Of these, 37 (57.8\%) had an IP, $23(35.9 \%)$ had a CSP, two (3.1\%) had a CP, and two (3.1\%) had an OP (Figure 2). The mean follow-up time was 41 months.

The characteristics of the study population are summarized in Table 1.

The median maternal age was 32 years $(22-45)$,. The median gestational age at diagnosis was 6.4 gestational weeks (GW) (4-12).

\subsection{Clinical symptomatology}

The most frequent symptomatology was the combination of metrorrhagia and pelvic pain (22 (34.4\%) patients. Fourteen (21.9\%) patients had no symptoms.

\subsection{Laboratory findings}

The median hCG level was 6089 IU/L (56-109740) at time of diagnosis of NTEP.

\subsection{Characteristics of NTEP on imaging}

The median of the largest diameter of the GS was 22 millimeters (2-66). (Figure 3).

\subsection{NTEP management (Table 2)}

The overall final success rate of conservative management was 92\% (59/64).

The overall initial success rate of conservative management was $57,8 \%(37 / 64)$. The median time for hCG resolution was $45(21-112)$ days and for NTEP disappearance on pelvic ultrasound 3.3 months (1-6).

\subsubsection{Expectant management (EM)}


Six patients (9.4\%) had a first-intention EM. The initial success rate was $50 \%(3 / 6)$. The final success rate was 100\% (6/6). Two (33.3\%) patients had an additional effective L-MTX injection because of HCG stagnation. One patient (16.7\%) with a CSP underwent second-line surgery (dilatation and curettage) for vaginal bleeding with retention. The average time for ultrasound resolution was 4.5 months.

\subsubsection{Systemic MTX injection (IM MTX) management}

Twenty-four (37.5\%) patients had first-intention IM-MTX. Initial primary management success was observed for 10 patients (41.7\%). The final success rate was $87.5 \%(21 / 24)$.

Four $(4 / 24,16.7 \%)$ patients had second-line surgical management (laparoscopic cornual resection for three IPs and ovariectomy by laparotomy for one OP) because of NTEP rupture for the OP and 2 IPs, and for evolution of the pregnancy for one IP despite the IM-MTX injection.

\subsubsection{Local MTX (L-MTX) injection management}

Twenty-eight patients (43.8\%) had first-intention L-MTX management. The injections were performed by laparoscopy for 11 patients (39.3\%) and by transvaginal-guided ultrasound for the remaining 17 (60.7\%). Initial primary management success was obtained for $18(64.3 \%)$ patient. The median time for hCG resolution was 54 days (21-91) and for a drop of $\geq 15 \%$ in hCG level 12 days. The median time for ultrasound resolution was 3.5 months (1-6).

Final success rates were $96,4 \%$ (27/28). One patient had a NTEP rupture treated by laparoscopic cornual resection.

\subsubsection{Other managements :}

\section{Datas are shown table 2.}

\subsection{Predictive factors}

No predictive factors for medical conservative management were found (table 3)

\subsection{Failure management.}


Rupture of the NTEP occur for five $(5 / 9,55 \%)$ patients. Three (one OP and 2 IPs) occurred during the IM-MTX follow-up (12,5\%, 3/24), another (IP) occurred immediately after the L-MTX injection by laparoscopy $(1 / 28,3,5 \%)$, and the last (CSP) after misoprostol management.

No hysterectomies were performed.

\subsection{Toxicity}

Two $(3.5 \%, 2 / 58)$ patients had serious side effects: one hepatic cytolysis and oral aphtosis (after C-MTX injection) and the other a hepatic cytolysis (after a unique L-MTX injection). Hepatic function returned to normal spontaneously in both cases.

\subsection{Long term follow-up:}

\subsubsection{Trophoblastic retention}

Four

patients

$(6.3 \%)$

had

trophoblastic

retention.

\subsubsection{Subsequent pregnancies}

Twenty-four patients (37.5\%) had 32 subsequent pregnancies, including 20 live births. The median time to pregnancy was $24(6-72)$ months after resolution of the NTEP. Seven miscarriages were recorded $(21.9 \%)$, three $(9.4 \%)$ recurrences of EP (one tubal EP and 2 NTEP) and one (3.1\%) elective abortion. Ten (50.0\%) patients had a vaginal delivery and nine $(45.0 \%)$ a cesarean section. One patient $(5 \%)$ had an artificial placental delivery for postpartum hemorrhage. No neonatal complications were found although five $(25.0 \%)$ newborns were small for their gestational age. Among the 13 patients with prior infertility, two (15.4\%) of them had a pregnancy including one recurrence of an IP and one live birth. 


\section{Discussion}

\subsection{Main Findings}

This study provides evidence to support that conservative medical management is highly effective with several MTX injections and safe to treat patients with NTEP with no or few symptoms wishing to preserve their fertility with a low risk of secondary surgery.

\subsection{Strengths and limitations}

We present a large series of 64 NTEPs managed by medical conservative treatment in a view to analyze the final successful outcomes (without emergency surgery) of conservative medical treatments. This was a pragmatic choice because the aim of conservative management is to avoid emergency surgery. Our study has some limitations. First, the final success rate does not evaluate the effectiveness of each type of management. This is why we took initial success as a secondary endpoint. Second, it was a retrospective study with a risk of bias such as loss of data and loss to follow-up. Nevertheless, the main information concerning the management of NTEP was collected without any loss. Third, its retrospective nature means that it was not possible to compare the initial success of IM-MTX and L-MTX as the pregnancies in the LMTX were more advanced. Finally, although the inclusion of three centers gave a good-sized patient sample in this rare condition, routine patient management varied from center to center which also hindered comparison.

\subsection{Interpretation}

The final success rate for all the conservative medical managements was $92.2 \%$ and the initial success rate was $54.7 \%$. These results are consistent with the literature $[9,11-13]$. The rate of second-intention surgery is similar to the other studies $[14,15]$. Contrary to some studies, no hysterectomy was necessary

[9].

The initial success rate for IM-MTX in our series was $41.7 \%$, which is lower than that usually reported. However, heterogeneity in study protocols and definitions of success somewhat complicates comparison between studies. In addition, several studies evaluate the efficacy of 
multiple MTX injections which is around $66 \%$ and $100 \%[11,16,17]$. We found an initial success rate of $64.3 \%$ for L-MTX and a final success rate of $96.4 \%$, which is similar to findings in literature, ranging from $70 \%$ to $100 \%[11,12,18-21]$. To achieve success, $37,5 \%$ of patients have additional MTX injection after IM-MTX management. After L-MTX injection, $28,5 \%$ of patients have one additional injection to achieve success. For EP, only $22,5 \%$ of patients achieve success with one dose [2].

In current practice, the choice between systemic or local injection of MTX is still a matter of debate. There is a theoretical risk of per- or postoperative bleeding at the injection site for local injection and this was experienced by one (3.6\%) patient in our series. The initial success rate was higher for L-MTX than for IM-MTX without reaching significance. Furthermore, the term of pregnancy and hCG levels were statistically higher in the L-MTX group rendering comparisons unrealistic. This can be explained by the strategy adopted by the medical team and practitioner's choice: L-MTX requires an obvious target lesionand would therefore be a more popular choice for later term pregnancies. In our study, the initial success rate of L-MTX for IPs was significantly higher than IM-MTX whereas this difference was not identified for CSPs. Nevertheless, to our knowledge, no other study has found this difference. Overall then, we are unable to conclude whether one injection modality of MTX is more effective than the other. This point deserves to be evaluated in prospective randomized studies. Nevertheless, $12.5 \%$ of the "lower" risk IM-MTX patients (3/24) had ruptured ectopics versus $3.6 \%(1 / 28)$ in the much "higher" risk patients in the L-MTX group. This data speaks to the more effective L-MTX therapy.

The choice of the first intention surgical management is still possible because of a high success rate. However, in the review of Mayeux et al, no comparison of treatment options between medical or surgical management was possible [22]. Surgical management can lead to hemorrhage and hemostasis hysterectomy risk with fertility impairment of these patients of childbearing age. In the present study, we present high final success rate with IM-MTX and LMTX injection with only $(7,8 \%)$ emergency surgery for 5 patients. No hysterectomy was 
performed. For EP, 5,8\% of patients require additional surgery after MTX treatment [2]. Thus, even if it is necessary to carry out several injections, this study highlight that medical management seems to be the best option to propose in first intention provided that it is under close supervision.

Fertility preservation is a major issue for women presenting with NTEP. Further studies must focus on this point 


\section{Acknowledgment}

To Matrix Consultants for proofreading in English and the corrections made.

\section{Contribution to authorship}

Sophie Delplanque, participated of the management of the patient, collected the data from patients, analysed them, and participated in writing the article. Marie Flévin, Sophie Le Gouic participated of the management of patient and collected the data from patient and analysed them. Maela Le Louis, Jean Leveque, Estelle Bauville, Pierre-Yves Moquet and Arnaud Fauconnier participated of the management of patient, Vincent Lavoué and Krystel Nyangoh Timoh analyzed the data and participated in the writing of the article.

\section{Ethics approval}

The study was approved by the Ethics Committee of the National College of the French Gynecologists and Obstetricians on the date of February 2, 2019 (CEROG 2018-GYN-1201).

\section{Funding statement}

The submission has no funders to report. 


\section{References}

[1] Skubisz MM, Horne AW, Johns TG, Nilsson UW, Duncan WC, Wallace EM, et al. Combination gefitinib and methotrexate compared with methotrexate alone to treat ectopic pregnancy. Obstetrics \& Gynecology 2013;122(4):745-51.

[2] Marret H, Fauconnier A, Dubernard G, Misme H, Lagarce L, Lesavre M, et al. Overview and guidelines of off-label use of methotrexate in ectopic pregnancy: report by CNGOF. European journal of obstetrics, gynecology, and reproductive biology 2016;205:105-9.

[3] Barnhart KT. Clinical practice. Ectopic pregnancy. The New England journal of medicine 2009;361(4):379-87.

[4] Bouyer J, Coste J, Fernandez H, Pouly JL, Job-Spira N. Sites of ectopic pregnancy: a 10 year population-based study of 1800 cases. Human reproduction (Oxford, England) 2002;17(12):3224-30.

[5] Hunt SP, Talmor A, Vollenhoven B. Management of non-tubal ectopic pregnancies at a large tertiary hospital. Reproductive biomedicine online 2016;33(1):79-84.

[6] Panelli DM, Phillips $\mathrm{CH}$, Brady PC. Incidence, diagnosis and management of tubal and nontubal ectopic pregnancies: a review. Fertility research and practice 2015;1:15.

[7] Parker VL, Srinivas M. Non-tubal ectopic pregnancy. Archives of gynecology and obstetrics 2016;294(1):19-27.

[8] Petersen KB, Hoffmann E, Larsen CR, Nielsen HS. Cesarean scar pregnancy: a systematic review of treatment studies. Fertility and sterility 2016;105(4):958-67.

[9] Ramkrishna J, Kan GR, Reidy KL, Ang WC, Palma-Dias R. Comparison of management regimens following ultrasound diagnosis of nontubal ectopic pregnancies: a retrospective cohort study. BJOG : an international journal of obstetrics and gynaecology 2017.

[10] ACOG Practice Bulletin No. 94: Medical management of ectopic pregnancy. Obstetrics and gynecology 2008;111(6):1479-85.

[11] Cassik P, Ofili-Yebovi D, Yazbek J, Lee C, Elson J, Jurkovic D. Factors influencing the success of conservative treatment of interstitial pregnancy. Ultrasound in obstetrics \& gynecology : the official journal of the International Society of Ultrasound in Obstetrics and Gynecology 2005;26(3):279-82.

[12] Cheung VY. Local Methotrexate Injection as the First-line Treatment for Cesarean Scar Pregnancy: Review of the Literature. Journal of minimally invasive gynecology 2015;22(5):753-8.

[13] Alalade AO, Smith FJE, Kendall CE, Odejinmi F. Evidence-based management of nontubal ectopic pregnancies. Journal of obstetrics and gynaecology : the journal of the Institute of Obstetrics and Gynaecology 2017;37(8):982-91.

[14] Hiersch L, Krissi H, Ashwal E, From A, Wiznitzer A, Peled Y. Effectiveness of medical treatment with methotrexate for interstitial pregnancy. The Australian \& New Zealand journal of obstetrics \& gynaecology 2014;54(6):576-80.

[15] Lau S, Tulandi T. Conservative medical and surgical management of interstitial ectopic pregnancy. Fertility and sterility 1999;72(2):207-15.

[16] Bodur S, Ozdamar O, Kilic S, Gun I. The efficacy of the systemic methotrexate treatment in caesarean scar ectopic pregnancy: A quantitative review of English literature. Journal of obstetrics and gynaecology : the journal of the Institute of Obstetrics and Gynaecology 2015;35(3):290-6. 
[17] Jermy K, Thomas J, Doo A, Bourne T. The conservative management of interstitial pregnancy. BJOG : an international journal of obstetrics and gynaecology 2004;111(11):1283-8.

[18] Kim MJ, Cha JH, Bae HS, Kim MK, Kim ML, Yun BS, et al. Therapeutic outcomes of methotrexate injection in unruptured interstitial pregnancy. Obstetrics \& gynecology science 2017;60(6):571-8.

[19] Verma U, English D, Brookfield K. Conservative management of nontubal ectopic pregnancies. Fertility and sterility 2011;96(6):1391-5. e1.

[20] Yamaguchi M, Honda R, Uchino K, Tashiro H, Ohba T, Katabuchi H. Transvaginal methotrexate injection for the treatment of cesarean scar pregnancy: efficacy and subsequent fecundity. Journal of minimally invasive gynecology 2014;21(5):877-83.

[21] Tanigaki S, Nagata C, Ueno K, Ozawa N, Nagaoka S, Tanaka K, et al. Successful Treatment of Caesarean Scar Pregnancies by Local Treatment Only. Obstetrics and gynecology international 2017;2017:9543570.

[22] Maheux-Lacroix S, Li F, Bujold E, Nesbitt-Hawes E, Deans R, Abbott J. Cesarean scar pregnancies: a systematic review of treatment options. Journal of minimally invasive gynecology 2017;24(6):915-25. 
Figure legends

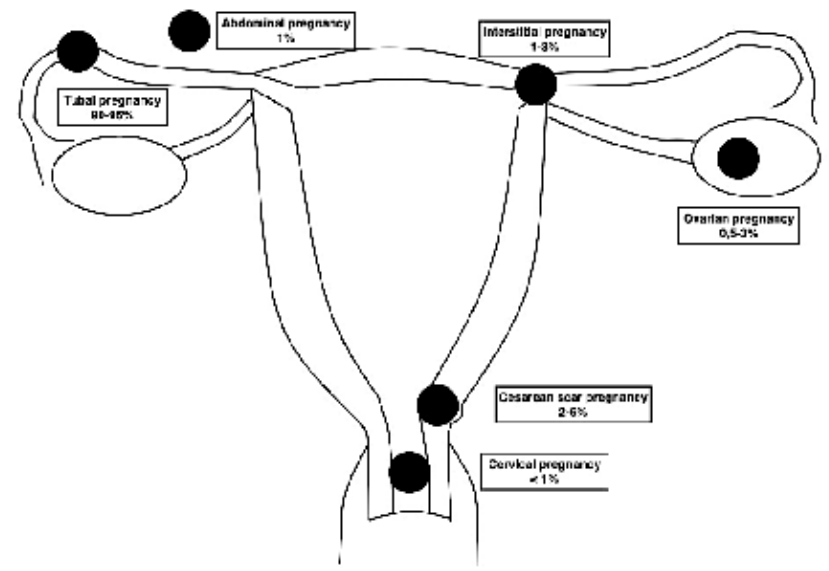

Figure 1: The classification and prevalence of ectopic pregnancies 


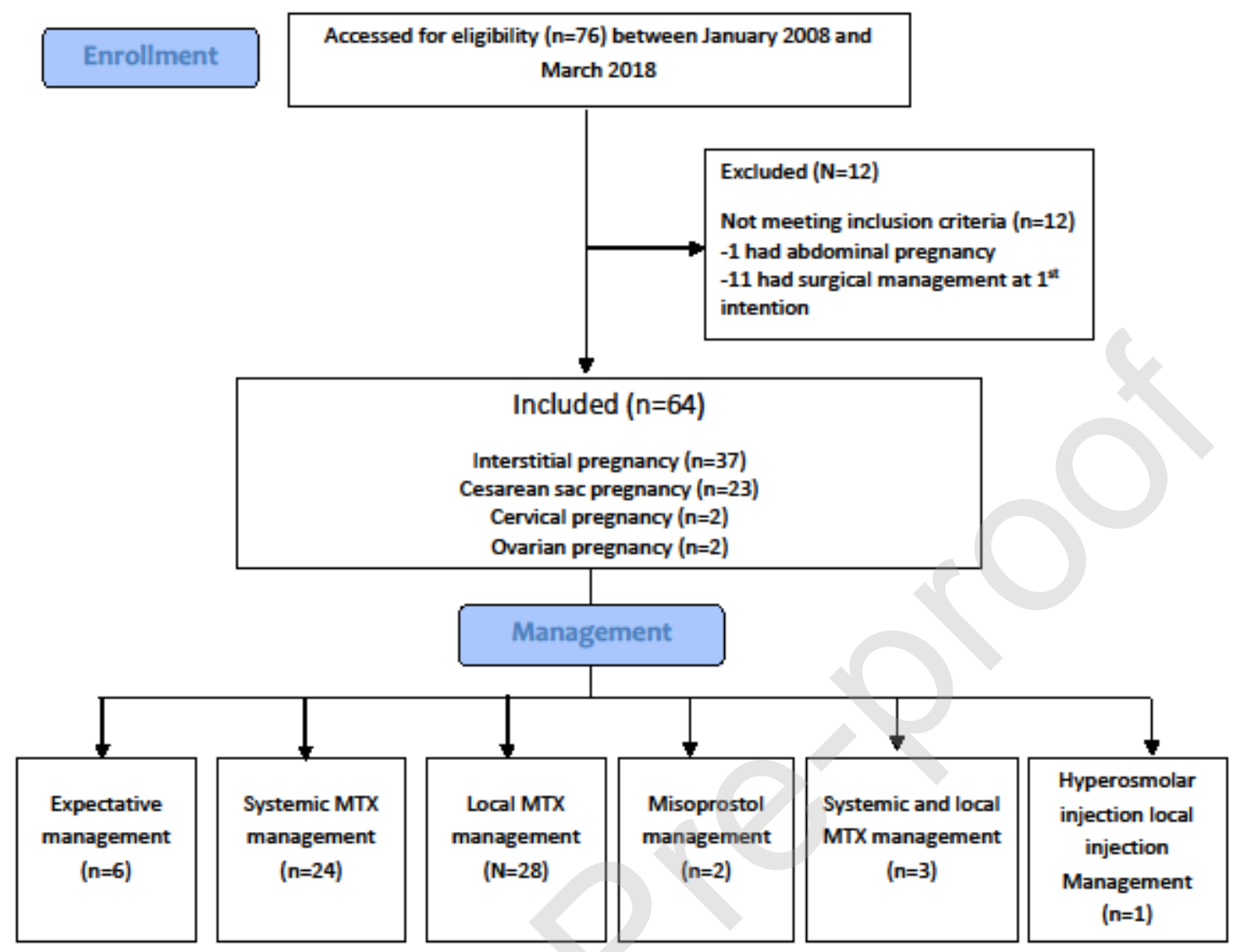

Figure 2: Flowchart original study 


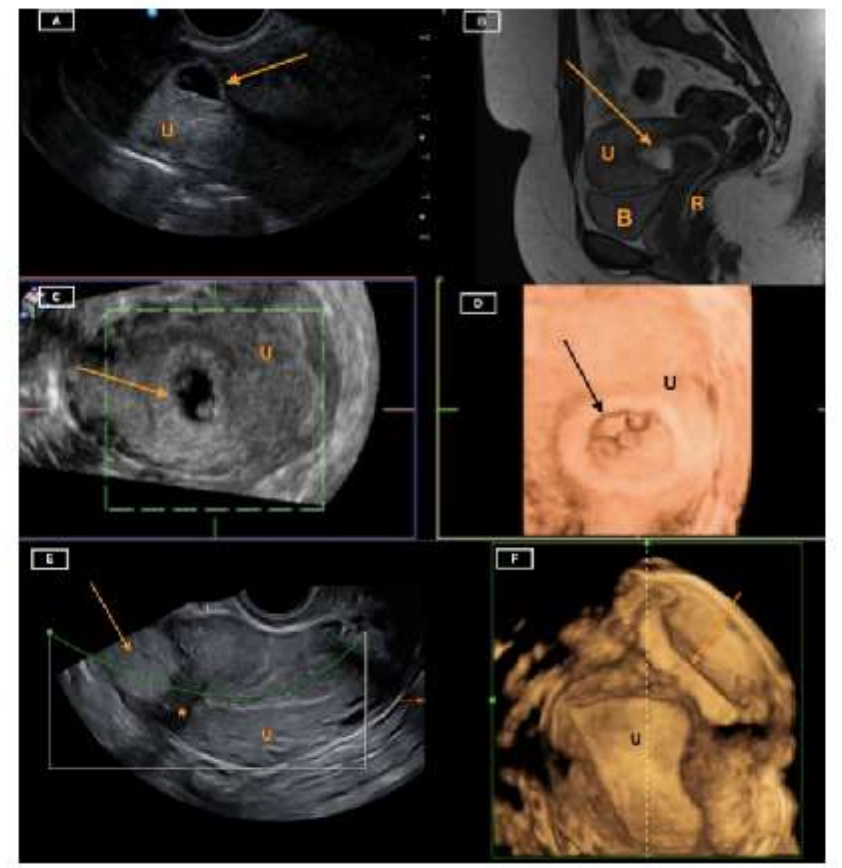

\section{Figure 3: Cesarean scar and interstitial pregnancy}

A: Transvaginal ultrasound image on sagittal axis shows an empty uterine cavity $(U)$ with an eccentric gestational sac (arrow) located in the anterior part of the uterine isthmus in the previous cesarean scar within the myometrial mantle.

B: Magnetic resonance imaging in Sagittal T2-weighted image shows a gestational sac (arrow) in the anterior part of uterine $(\mathrm{U})$ isthmus. A thin myometrium is between the bladder $(B)$ and the gestational sac. (R: Rectum) 
C: Transvaginal ultrasound image on axial axis and D: 3D reconstruction shows the gestational sac (arrow) in the anterior part of the uterine isthmus (U).

E: Transvaginal ultrasound image on sagittal axis shows an Empty uterine cavity $(U)$ with an eccentric trophoblastic mass (arrow) located in the interstitial portion of the fallopian tube. There is the echogenic line called interstitial sign $\left({ }^{*}\right)$ extending from the uterine cavity to the gestational sac.

F: Transvaginal ultrasound image 3D reconstruction on axial axis shows an empty uterine cavity $(U)$ with an eccentric trophoblastic mass (arrow) separated from the endometrium. 


\section{Table legends}

\section{Table 1: Patient characteristics of the study population}

Total $\mathrm{N}=64$

\section{Epidemiologic Characteristics}

Median maternal age (years) (min-max)

$32(22-45)$

Median gravidity (min-max)

$3(1-11)$

Median parity (min-max)

$1(0-5)$

Median BMI $\left(\mathrm{kg} / \mathrm{m}^{2}\right)$ (min-max)

$25.9(16.7-40.6)$

Risk factor for ectopic pregnancy

Smoking Tabaco n (\%)

$10(15.6)$

Age $>35$ years $n(\%)$

Intrauterine device $\mathrm{n}(\%)$

$19(29.7)$

Progesterone-only pill / Implant $\mathrm{n}(\%)$

$5(7.8)$

History of ectopic pregnancy $n(\%)$

$18(28.1)$

History of pelvic inflammatory disease $n(\%)$

$2(3.1)$

Previous Infertility n (\%)

Assisted reproduced techniques $\mathrm{n}(\%)$

History of endometriosis $\mathrm{n}(\%)$

Previous miscarriages $\mathrm{n}(\%)$

Previous dilatation and curettage $\mathrm{n}(\%)$

History of uterine surgery $n(\%)$

History of pelvic surgery $n(\%)$

Previous cesarean section $n(\%)$

History of uterine fibroids $n(\%)$

\section{Diagnostic characteristics}

Median gestational age on diagnosis (gestational weeks) (min-max)

$6.4(4-12)$

Clinical:

No symptoms $n(\%)$

Pelvic pain $\mathrm{n}(\%)$

Metrorrhagia $n(\%)$

$11(17.2)$

Metrorrhagia and pelvic pain $\mathrm{n}(\%)$

Hemodynamically unstable $\mathrm{n}(\%)$

\section{Laboratory results:}

Median hCG (IU/L) (min-max)

Median progesterone $(\mathrm{ng} / \mathrm{mL})$ (min-max)

\section{Imaging findings:}

Median of the largest diameter of the gestational sac (mm) (min-

max)

Visualized fetus $\mathrm{n}(\%)$

Mean fetal crown-rump length $(\mathrm{mm})$

Fetal cardiac activity $n(\%)$

Abdominal Bleeding $n(\%)$

Second-line exam n (\%) 
Exploratory laparoscopy $n(\%)$ $1(1.6)$

Average time for hCG resolution (days)

Average time for sonography resolution (months)

BMI: Body Mass Index

hCG: Human Chorionic Gonadotropin

MRI: magnetic resonance imaging

Table 2: Success rate of medical conservative management and complications

Table 2: Success rate of conservative medical management and complications

\begin{tabular}{|c|c|c|c|c|c|c|}
\hline & Total $\mathrm{N}=6$ & Total $\mathrm{N}=24$ & $\begin{array}{c}\text { L-MTX } \\
\text { Total N=28 }\end{array}$ & Total $\mathrm{N}=3$ & Misoprostol & $\begin{array}{l}\text { Hyperosm } \\
\text { olar } \\
\text { serum } \\
\text { Total } \mathrm{N}=1\end{array}$ \\
\hline Initial success n (\%) & $3(50)$ & $10(41.7)$ & $18(64.3)$ & $3(100)$ & 0 & $1(100)$ \\
\hline Final success n (\%) & $5(83.3)$ & $20(83.3)$ & 25 (89.3) & $3(100)$ & $1(50)$ & $1(100)$ \\
\hline $\begin{array}{l}\text { Median initial HCG (UI/L) } \\
\text { (min-max) }\end{array}$ & $\begin{array}{r}3693 \\
(199- \\
59483)\end{array}$ & $\begin{array}{r}3732(56- \\
36024)\end{array}$ & $\begin{array}{l}24489 \\
(1889- \\
85364)\end{array}$ & $\begin{array}{r}66733 \\
(2713- \\
109740)\end{array}$ & 42 & 1123 \\
\hline $\begin{array}{l}\text { Average time interval for } \\
\text { HCG resolution (days) } \\
\text { (initial/Final success) }\end{array}$ & $72 / 62$ & $35 / 42$ & $57 / 57$ & $70 / 70$ & $\mathrm{X} / 42$ & $28 / 28$ \\
\hline $\begin{array}{l}\text { Average time for } 15 \% \\
\text { decrease of HCG (days) } \\
\text { Initial/Final success }\end{array}$ & 12 & $11 / 13$ & $11 / 12$ & $9 / 9$ & $\mathrm{X} / 14$ & $7 / 7$ \\
\hline Complications n (\%) & $2(33.3)$ & $5(20.8)$ & $4(14.3)$ & $2(66.7)$ & $1(50)$ & 0 \\
\hline NTEP Rupture n (\%) & 0 & $3(12.5)$ & $1(3.6)$ & 0 & $1(50)$ & 0 \\
\hline Blood transfusion $\mathrm{n}(\%)$ & $1(16.7)$ & $1(4.2)$ & $1(3.6)$ & $1(33.3)$ & 0 & 0 \\
\hline Genital bleeding n (\%) & $1(16.7)$ & $3(12.5)$ & $2(7.1)$ & $1(33.3)$ & $1(50)$ & 0 \\
\hline $\begin{array}{r}\text { Surgical complication } n \\
(\%)\end{array}$ & 0 & 0 & $1(3.6)$ & 0 & $1(50)$ & 0 \\
\hline $\begin{array}{r}\text { Trophoblastic retention } n \\
(\%)\end{array}$ & $1(16.7)$ & $1(4.2)$ & $2(7.1)$ & 0 & 0 & 0 \\
\hline $\begin{array}{r}\text { Side effect from MTX } n \\
(\%)\end{array}$ & 0 & 0 & $1(3.6)$ & $1(33.3)$ & 0 & 0 \\
\hline Hysterectomy n (\%) & 0 & 0 & 0 & 0 & 0 & 0 \\
\hline
\end{tabular}


EM: Expectant management

IM-MTX: systemic methotrexate injection

L-MTX: local Methotrexate injection

C-MTX: combined Methotrexate

hCG: Human Chorionic Gonadotropin

NTEP: Non-Tubal Ectopic Pregnancy 
Table 3: Initial success rate according to the site of the ectopic pregnancy

\begin{tabular}{|c|c|c|c|c|c|c|c|c|c|c|c|c|c|c|}
\hline \multirow{2}{*}{$\begin{array}{l}\text { Site of } \\
\text { ectopic } \\
\text { pregnancy }\end{array}$} & \multirow{2}{*}{$\begin{array}{l}\begin{array}{l}\text { Case by } \\
\text { site }\end{array} \\
\mathrm{N}(\%)\end{array}$} & \multirow{2}{*}{$\begin{array}{l}\text { Median } \\
\text { gestational } \\
\text { age } \\
\text { GW (min- } \\
\text { max) }\end{array}$} & \multicolumn{2}{|c|}{$\begin{array}{l}\text { Expectant } \\
\text { management }\end{array}$} & \multicolumn{2}{|c|}{ IM-MTX } & \multicolumn{2}{|c|}{ L-MTX } & \multicolumn{2}{|c|}{ Misoprostol } & \multicolumn{2}{|c|}{ G30 } & \multicolumn{2}{|c|}{ MTX C } \\
\hline & & & $\mathrm{N}$ & $\begin{array}{l}\text { Initial } \\
\text { success } \\
\text { rate N } \\
(\%)\end{array}$ & $\mathrm{N}$ & $\begin{array}{l}\text { Initial } \\
\text { success } \\
\text { rate N } \\
(\%) \\
\end{array}$ & $\mathrm{N}$ & $\begin{array}{l}\text { Initial } \\
\text { success } \\
\text { rate N } \\
(\%)\end{array}$ & $\mathrm{N}$ & $\begin{array}{l}\text { Initial } \\
\text { success } \\
\text { rate N } \\
(\%) \\
\end{array}$ & $\mathrm{N}$ & $\begin{array}{l}\text { Initial } \\
\text { success } \\
\text { rate N } \\
(\%) \\
\end{array}$ & $\mathrm{N}$ & $\begin{array}{l}\text { Initial } \\
\text { success rate } \\
\mathrm{N}(\%)\end{array}$ \\
\hline CSPS & $23(35,9)$ & $6,4(4-12)$ & 5 & $2(40)$ & 6 & $5(83,3)$ & 10 & $5(50)$ & 1 & $0(0)$ & 0 & & 1 & $1(100)$ \\
\hline IPs & $37(57,8)$ & $\begin{array}{l}6,4(4- \\
11,5)\end{array}$ & 1 & $1(100)$ & 14 & $4(28,6)$ & 18 & 13(72) & 1 & $0(0)$ & 1 & $1(100)$ & 2 & $2(100)$ \\
\hline $\mathrm{CP}$ & $2(3,1)$ & $7,5(7-8)$ & 0 & & 2 & $1(50)$ & 0 & & 0 & & 0 & & 0 & \\
\hline OP & $2(3,1)$ & $5,2(4-6,4)$ & 0 & & 2 & $1(50)$ & 0 & & 0 & & 0 & & 0 & \\
\hline
\end{tabular}

GW: Gestational weeks

IP: Interstitial Pregnancy

CSP: Cesarean scar pregnancy

$\mathrm{CP}$ : Cervical pregnancy

OP: Ovarian pregnancy

IM-MTX: systemic methotrexate injection

L-MTX: local Methotrexate injection 